\title{
Dilated Cardiomyopathy Compatible With Sarcoidosis Presenting with Syncope Due to Torsades de Pointes: a Case Report
}

Carollina Fernandes Tinoco ${ }^{1}$, Nathalia Rodrigues Perrenoud Branca1, Gabriela Domingues Carvalho', Lívia Silva de Paula Faria ${ }^{1}$, Erivelton Alessandro do Nascimento ${ }^{1,2, *}$

\section{ORCID IDs}

Tinoco CF (D) https://orcid.org/0000-0002-3256-8798

Branca NRP (D) https://orcid.org/0000-0002-7055-7109

\author{
Carvalho GD (D) https://orcid.org/0000-0003-4942-9273 \\ Faria LSP (D) https://orcid.org/0000-0002-5796-4236 \\ Nascimento EA (D) https://orcid.org/0000-0001-8260-6572
}

\begin{abstract}
Sarcoidosis is a multisystemic noncaseating granulomatous disease of unknown etiology. Cardiac sarcoidosis clinical presentation is diverse, and syncope is one of the possible primary events. Due to its variable natural history and initial presentation associated with lacking sensitive and specific diagnostic tests, it still represents a challenging diagnosis. This article presents the case of a 51-year-old female patient with intermittent syncope events associated with torsades de pointes and dilated cardiomyopathy compatible with sarcoidosis.
\end{abstract}

KEYWORDS: Sarcoidosis; Syncope; Cardiac arrhythmias; Magnetic resonance imaging.

\section{INTRODUCTION}

Sarcoidosis is a rare systemic inflammatory noncaseating granulomatous disease of unknown etiology that usually affects adults between the ages of 25 and $45^{1}$. Basic pathogenesis involves resolving inflammation areas that tend to evolve to myocardial scarring tissue, providing the substrate for reentry circuits ${ }^{2}$. Upon this scenario, the inflammatory affection of myocardial tissue stablishes cardiac sarcoidosis (CS), that might present with electrical abnormalities, including ventricular arrhythmias and atrioventricular (AV) blocks ${ }^{3}$, but also syncope ${ }^{4-7}$, heart failure and even cardiac tamponade ${ }^{8}$. The most common electrical abnormality is third degree AV block, followed by ventricular tachycardia $(\mathrm{VT})^{2}$.

The exact prevalence of isolated cardiac sarcoidosis is uncertain ${ }^{9}$. It is estimated that up to a quarter of patients with sarcoidosis might present $\mathrm{CS}^{10}$, but only $5 \%$ manifest cardiac involvement clinically ${ }^{4}$. In parallel, up to $20 \%$ of CS patients

1. Centro Universitário de Volta Redonda - Volta Redonda/RJ - Brazil.

2. Universidade Federal Fluminense - Hospital Universitário Antônio Pedro - Niterói/RJ - Brazil.

*Corresponding author: hpcrates7@gmail.com

Received: Aug 12, 2020 | Accepted: Dec 07, 2020 
present a clinically silent disease ${ }^{11}$ with asymptomatic cardiac involvement, not identified by diagnostic criteria. Cardiac sarcoidosis patients may present with higher morbidity and mortality rates, with overall 5-year survival around $60 \%{ }^{12}$.

A recent study showed that sudden cardiac death (SCD) constitutes up to $14 \%$ of the presenting manifestations of $\mathrm{CS}$ and as many as $80 \%$ of all fatalities in that group. It also states that almost $66 \%$ of fatalities occur suddenly, due to undiagnosed intracardiac granulomas ${ }^{13}$, thus configuring $\mathrm{SCD}$ as one of the most feared clinical implications of this disease.

Although at present there is no specific optimal screening or risk stratification strategy for $\mathrm{SC}$ patients ${ }^{12}$, guidelines refer to clinical, radiologic, and immunohistologic criteria for diagnosing cardiac sarcoidosis ${ }^{1}$, which might be established on a histological or clinical basis. Considering iatrogenic risks related to endomyocardial biopsy ${ }^{13}$ and its low sensitivity ${ }^{14}$, individualized diagnostic approach and accurate noninvasive diagnosis is desirable.

If there is no previous diagnosis of extracardiac sarcoidosis, clinical suspicion should occur if the patient is below 60 years and has no prior history of sarcoidosis but presents: (a) Mobitz II AV block; or (b) third degree AV block; or (c) sustained VT; or (d) heart failure with reduced or preserved left ventricle ejection fraction (LVEF) of unclear etiology ${ }^{15}$.

The objective of this report is to present a case of a 51-year-old patient with syncope events associated with torsades de pointes identified in the 24-hour Holter and dilated cardiomyopathy compatible with CS.

\section{CASE REPORT}

A 51-year-old white female patient, with no previous comorbidities, presented to an outpatient cardiology clinic with a complaint of a 4-month intermittent repeated syncope. The events were preceded by dizziness. Sporadic episodes of palpitation and vertigo have also been reported. She was not taking any cardioactive medications. The family history was negative for SCD.

Electrocardiogram showed sinus rhythm, complete right bundle branch block, left anterior hemiblock associated with ventricular ectopic beats. On 24-hour electrocardiogram (ECG) Holter monitoring (Fig. 1), it was found that a syncope event was preceded by a torsades de pointes that degenerated into ventricular fibrillation.

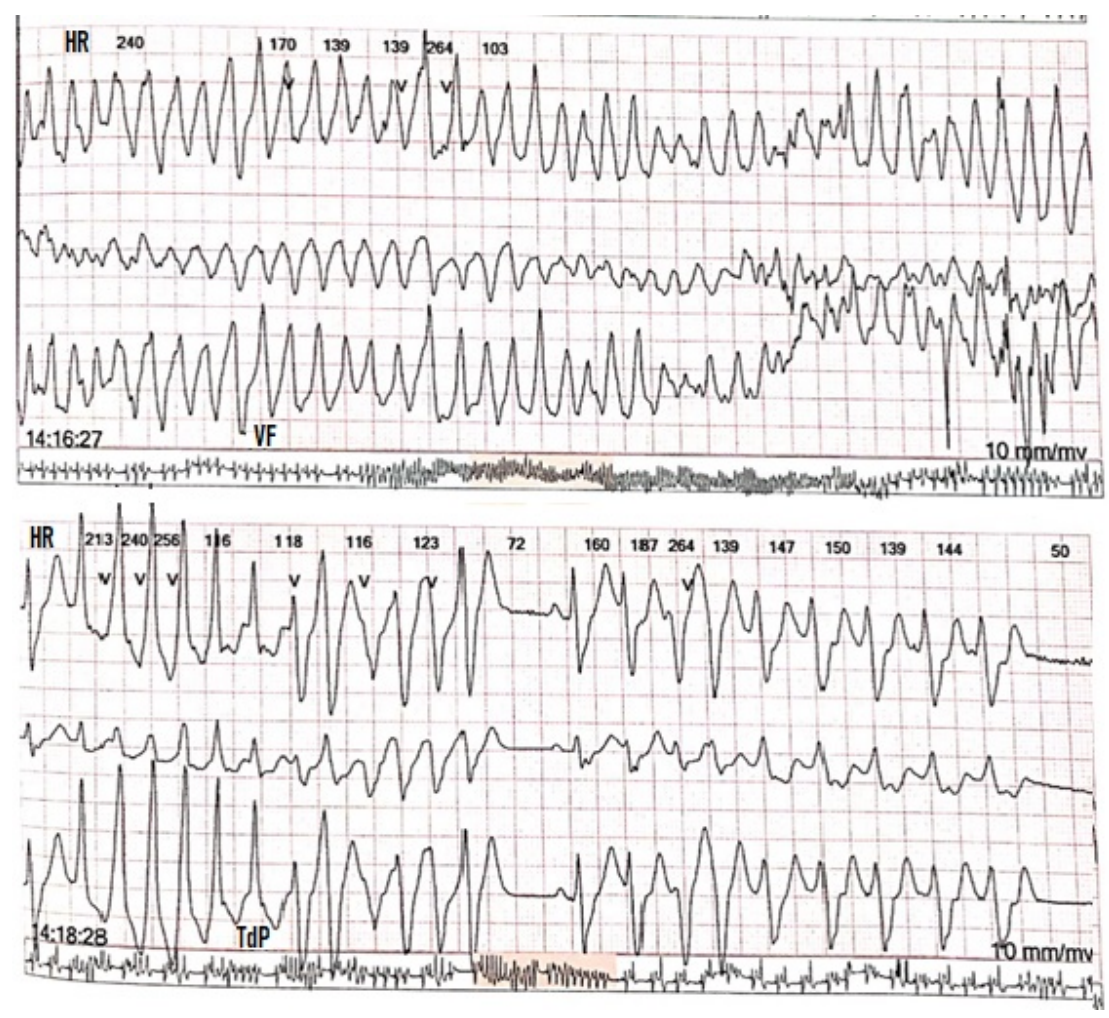

Figure 1. 24-hour ECG Holter. 24-hour Holter monitor records of torsade de pointes (TdP). HR: heart rate; VF: ventricular fibrillation. 
Cardiac magnetic resonance imaging (MRI) (Fig. 2) was also performed, showing: (1) mild left atrium dilation (2) mild systolic LV dysfunction; (3) akinesia of the (a) inferior, septal and basal; and (b) inferior, septal and medial segments; (4) delayed enhancement pattern of moderate degree in mesocardium, with transmural involvement of the above-mentioned segments, favoring CS diagnosis. The ${ }^{67}$ gallium scintigraphy was inconclusive.

Transthoracic echocardiography (TTE) identified a dilated cardiomyopathy with left atrium enlargement, diffuse hypokinesia and mild to moderate left ventricle (LV) dysfunction with an LVFE of 45\%. Laboratory tests showed no abnormalities. At this point, the patient received a target dose prescription of sacubitril/valsartan, bisoprolol and amiodarone and an indication of implantable cardioverter-defibrillator (ICD).

Based on these findings, the diagnostic hypothesis was nonischemic myocardial injury, consistent with CS or previous episode of myocarditis. Thus, the patient underwent ICD implantation. Three episodes of sustained ventricular arrhythmias were documented in the first six months after ICD implantation and no new episodes of syncope were registered or reversed six months before this report. Although endomyocardial biopsy is required for histopathological confirmation of CS, the patient opted not to undergo the procedure due to the related iatrogenic risks.
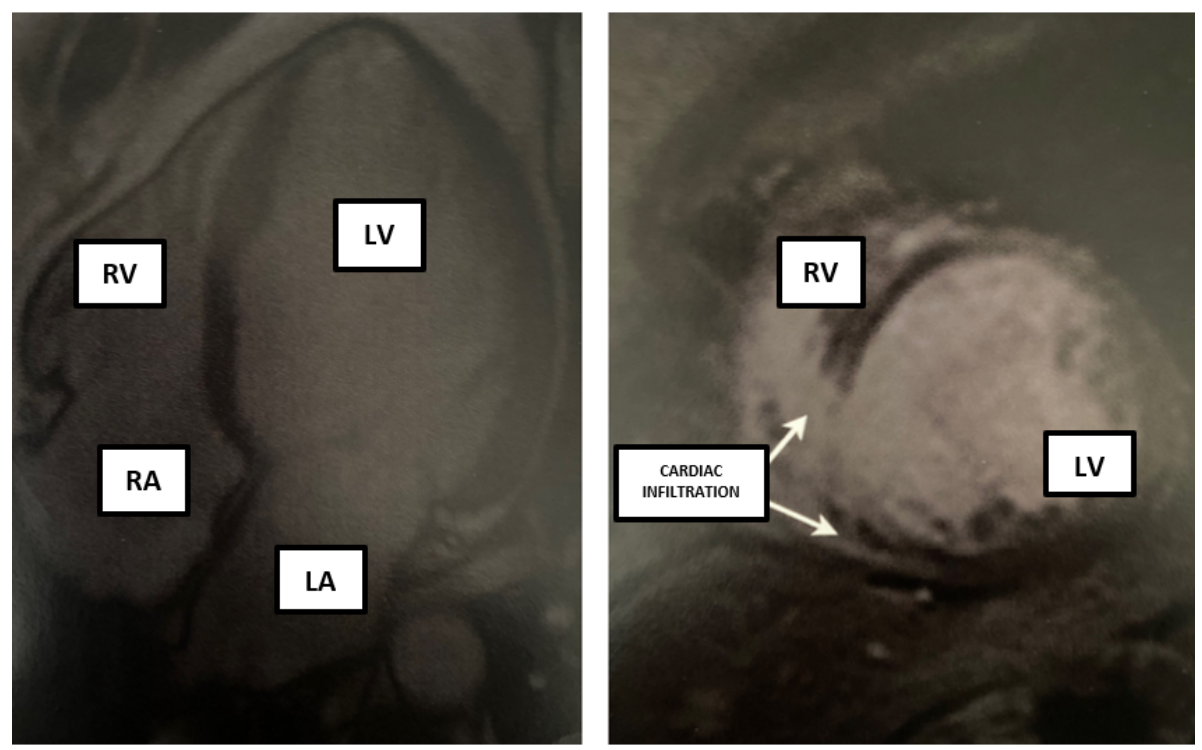

Figure 2. Cardiac magnetic resonance imaging. CMRI: moderate heterogeneous late enhancement of inferior, septal and basal mesocardium segments. RV: right ventricle; LV: Left ventricle; RA: right atrium; LA: Left atrium.

\section{DISCUSSION}

Although endomyocardial biopsies (EMBs) may provide a definitive SC diagnosis, it presents practical limitations related to the focal nature of the disease and to the method itself, such as poor sensitivity (with diagnostic yield varying from 13 to $35 \%$, among studies), high false negative rates, invasiveness and complications associated with tissues sampling , $3,13,14,16-18^{\text {. }}$

One way to improve EMBs indicators is to associate electroanatomic voltage mapping (EVM). The largest cohort of patients undergoing EVM-guided EMB compared it with a cardiac magnetic resonance (CMR) guided approach. It was pointed out that EVM presents similar sensitivity rates to CMR (74\% versus $77 \%$ ), with higher specificity levels (70\% versus $47 \%$ ). On the one hand, it is suggested that EVM accuracy rate is close to CMR and that such methods combined grant $\mathrm{EMB}$ a positive predictive value of $89 \%$, with low complication rates. On the other hand, it is pointed out that the absence of pathological findings at CMR and EVM does not reliably exclude $\mathrm{CS}^{19}$.

In clinical practice, relatively few cases are definitively diagnosed through histologic parameter ${ }^{20}$. Since early diagnosis is of paramount importance to best prognosis, imaging represents vital noninvasive and sensitive methods ${ }^{17}$ and there are 
some available modalities ${ }^{18}$. In this scenario, a combination of clinical, electrocardiographic and imaging criteria seems to be desirable and can be relied upon to provide probabilistic diagnosis ${ }^{16}$.

In the past few years, many studies have shown the diagnostic utility of 2-deoxy-2-[fluorine-18]fluoro-D-glucose, or ${ }^{18} \mathrm{~F}-\mathrm{FDG} \mathrm{PET} / \mathrm{CT}$, in patients with $\mathrm{CS}^{21}$. A recent systematic review with meta-analysis revealed the sensitivity of the method was $84 \%$ (95\% confidence interval [95\% CI] 0.71-0.91) with specificity of $83 \%$ (95\% CI 0.74-0.89) for detection of cardiac sarcoidosis ${ }^{22}$. Compared to MRI, the advantages of ${ }^{18} \mathrm{~F}-\mathrm{FDG}$ PET/CT are: (1) provision of metabolic information; (2) detection of active inflammation; (3) potential for determine cardiac and extracardiac involvement; and (4) contemplation of patients with implantable cardiac devices, non-MRI compatible, or chronic renal failure ${ }^{23}$. Despite both methods seem to be effective for the detection of CS, there is no formal consensus on which imaging modality is preferred ${ }^{18}$.

The Japanese Circulation Society (JCS) suggests an innovative strategy that enables the establishment of clinical diagnosis of CS without any histopathological evidence of sarcoidosis ${ }^{14}$. For such, patients must present "CS-specific cardiovascular findings" and histopathological or clinical diagnosis of extracardiac sarcoidosis and F-FDG PET is considered mandator $\mathrm{y}^{24}$. The patient presented in this case report showed two criteria of primary findings: (1) clinical evidence of cardiac manifestation, such as torsades de pointes; and (2) late gadolinium enhancement (LGE) with CMR. Although it is not possible to establish a diagnose of CS based on such parameters, since FDG PET criteria were not established. Nonetheless, the existence of criteria that prescind from histopathology emerges as a new paradigm on this scenario, that may be useful for other patients. Finally, CS screening tests should be developed to diagnose CS before it causes symptoms and important morbidity and mortality ${ }^{18}$.

Implantable cardioverter-defibrillator implantation is a therapeutic mainstay for prevention of SCD in CS and some of the implantation criteria include: (1) sustained VT or survivors of sudden cardiac arrest (2) LVEF of 35\% or less; (3) patients with LVEF greater than 35\% who have syncope and/or evidence of myocardial scar by cardiac MRI or PET scan, and/or have an indication for permanent pacing implantation of an ICD reasonable; (4) patients with LVEF greater than 35\%, in whom it is reasonable to perform an electrophysiological study and to implant an ICD, if sustained ventricular arrhythmias (VA) is inducible; (5) patients who have an indication for permanent pacing; (6) patients with frequent symptomatic VA and evidence of myocardial inflammation, immunosuppression in combination with antiarrhythmic medication therapy ${ }^{25}$. Based on that, the patient received an ICD implantation, with satisfactory results: no more syncope or SCD episodes have been registered 2 years later. It should also be noted that three episodes of sustained VT were reverted due to antitachycardia pacing therapies delivery on the same period.

\section{CONCLUSIONS}

Cardiac sarcoidosis remains an enigma with an uncertain etiology and a challenging diagnosis, which leads to potentially serious adverse outcomes. Since the early diagnosis is of paramount importance to best prognosis and that, in clinical practice, relatively few cases are definitively diagnosed through histologic parameters, a combination of clinical, electrocardiographic and imaging criteria seems to be desirable and can be relied upon to provide probabilistic diagnosis. Prevention of SCD is a vital part of the conduct that also involves optimized pharmacological treatment and ICD implantation as a mainstay.

\section{AUTHORS' CONTRIBUTION}

Conceptualization: Tinoco F. C., Branca N. R. P., Carvalho G. D., Faria L. S. P. and Nascimento E. A.; Methodology: Tinoco F. C., Branca N. R. P., Carvalho G. D., Faria L. S. P. and Nascimento E. A.; Writing - Original Draft: Tinoco F. C., Branca N. R. P., Carvalho G. D., Faria L. S. P. and Nascimento E. A.; Writing-Review and Editing: Nascimento E. A. Supervision: Nascimento E. A. 


\section{REFERENCES}

1. Serei VD, Fyfe B. The many faces of cardiac sarcoidosis. Am J Clin Pathol. 2020;153(3):294-302. https://doi.org/10.1093/ajcp/aqz169

2. Youssef G, Beanlands RSB, Birnie DH, Nery PB. Cardiac sarcoidosis: applications of imaging in diagnosis and directing treatment. Heart. 2011;97(24):2078-87. https://doi.org/10.1136/hrt.2011.226076

3. Mankad P, Mitchell B, Birnie D, Kron J. Cardiac sarcoidosis. Curr Cardiol Rep. 2019;21(12):152. https://doi.org/10.1007/s11886-019$1238-1$

4. Tan JL, Sharma SK. Cardiac sarcoidosis presenting with syncope and rapidly progressive atrioventricular block: a case report. Eur Heart J Case Rep. 2018;2(4):yty103. https://doi.org/10.1093/ehjcr/yty103

5. Thangam M, Nathan S, Kar B, Petrovic M, Patel M, Loyalka P, et al. Primary cardiac sarcoidosis with syncope and refractory atrial arrhythmia: a case report and review of the literature. Tex Heart Inst J. 2016;43(3):236-40. https://doi.org/10.14503/THIJ-14-4792

6. Lenge W, Zurick AO, Yaddanapudi K, Flamm SD, Tan CD, Bolen MA. Cardiac and pulmonary sarcoidosis presenting as syncopal episode: Report of two cases. Radiology Case Reports. 2011;6(4):536. https://doi.org/10.2484/rcr.v6i4.536

7. Noor A, Bhatti W, Masood J. Syncope: a life-threatening presentation for cardiac sarcoidosis. Chest. 2019;156(4):A388. https://doi. org/10.1016/j.chest.2019.08.425

8. Verdickt S, De Man F, Haine E, Van Cleemput J. Sarcoidosis presenting as cardiac tamponade: a case report. Acta Clin Belg. 2020;30;1-5. https://doi.org/10.1080/17843286.2020.1724429

9. Arkema EV, Cozier YC. Epidemiology of sarcoidosis: current findings and future directions. Ther Adv Chronic Dis. 2018;9(11):227-40. https://doi.org/10.1177/2040622318790197

10. Hulten E, Aslam S, Osborne M, Abbasi S, Bittencourt MS, Blankstein R. Cardiac sarcoidosis - state of the art review. Cardiovasc Diagn Ther. 2016;6(1):50-63. https://doi.org/10.3978/j.issn.2223-3652.2015.12.13

11. Ipek E, Demirelli S, Ermis E, Inci S. Sarcoidosis and the heart: A review of the literature. Intractable Rare Dis Res. 2015;4(4):170-80. https://doi.org/10.5582/irdr.2015.01023

12. Kouranos V, Wells AU, Sharma R. Treatment of cardiac sarcoidosis. Curr Opin Pulm Med. 2019;25(5):519-25. https://doi.org/10.1097/ mcp.0000000000000611

13. Antunes H, Gil J, Marmelo B, Gonçalves ML, Pires MI, Santos JM, et al. latrogenic complications during the diagnostic work-up of an inflammatory cardiomyopathy. Int J Cardiovasc Sci. 2020;33(6):729-33. https://doi.org/10.36660/ijcs.20190153

14. Tsushima T, Sasaki S, Yuda S, Ohta M, Cammack I, Sato H, et al. Remaining challenges in the diagnosis of early stage cardiac sarcoidosis. Clin Case Rep. 2019;7(5):1007-11. https://doi.org/10.1002/ccr3.2114

15. Kopřiva P, Gřiva M, Tüdös Z. Management of cardiac sarcoidosis - A practical guide. Cor Vasa. 2018;60(2):e155-64. https://doi. org/10.1016/j.crvasa.2017.05.012

16. Elwazir MY, Bois JP, Ezzeddine OFA, Chareonthaitawee P. Imaging and quantification of cardiac sarcoidosis. Semin Nucl Med. 2020;50(4):283-94. https://doi.org/10.1053/j.semnuclmed.2020.03.005

17. Birnie DH, Sauer WH, Bogun F, Cooper JM, Culver DA, Duvernoy CS, et al. HRS expert consensus statement on the diagnosis and management of arrhythmias associated with cardiac sarcoidosis. Heart Rhythm. 2014 Jul;11(7):1304-23. https://doi.org/10.1164/ rccm.202002-0251st

18. Crouser ED, Maier LA, Wilson KC, Bonham CA, Morgenthau AS, Patterson KC, et al. Diagnosis and detection of sarcoidosis. An Official American Thoracic Society Clinical Practice Guideline. Am J Respir Crit Care Med. 2020;201(8):e26-51. https://doi.org/10.1164/ rccm.202002-0251ST

19. Casella M, Dello Russo A, Bergonti M, Catto V, Conte E, Sommariva E, et al. Diagnostic yield of electroanatomic voltage mapping in guiding endomyocardial biopsies. Circulation. 2020;142(13):1249-60.

20. Uemura A, Morimoto S, Hiramitsu S, Kato Y, Ito T, Hishida H. Histologic diagnostic rate of cardiac sarcoidosis: evaluation of endomyocardial biopsies. Am Heart J. 1999;138(2):299-302. https://doi.org/10.1016/s0002-8703(99)70115-8

21. Wiefels C, Lamai O, Kandolin R, Birnie D, Leung E, Mesquita CT, et al. The role of 18F-FDG PET/CT in cardiac sarcoidosis. Int J Cardiovasc Sci. 2020;33(4):389-400. http://doi.org/10.36660/ijcs.20200033 
22. Kim S-J, Pak K, Kim K. Diagnostic performance of F-18 FDG PET for detection of cardiac sarcoidosis; A systematic review and metaanalysis. J Nucl Cardiol. 2019;27(6):2103-15. https://doi.org/10.1007/s12350-018-01582-y

23. Mastrocola LE, Amorim BJ, Vitola JV, Brandão SCS, Grossman GB, Lima RSL, et al. Atualização da Diretriz Brasileira de Cardiologia Nuclear - 2020. Arq Bras Cardiol. 2020;114(2):325-429. https://doi.org/10.36660/abc.20200087

24. Terasaki F, Yoshinaga K. New guidelines for diagnosis of cardiac sarcoidosis in Japan. Annals of Nuclear Cardiology. 2017;3(1):42-5. https://doi.org/10.17996/anc.17-00042

25. Al-Khatib SM, Stevenson WG, Ackerman MJ, Bryant WJ, Callans DJ, Curtis AB, et al. 2017 AHA/ACC/HRS guideline for management of patients with ventricular arrhythmias and the prevention of sudden cardiac death: executive summary. Circulation. 2018;138(13):e210-71. https://doi.org/10.1161/cir.0000000000000548 